Aim of the study: We demonstrated stimulation of both erythrocyte immune function and superoxide dismutase activity in tumor-bearing mice in response to whole-body $75 \mathrm{mGy}$ X-rays. In addition, we enhanced the chemotherapeutic effect by exposing tumor-bearing mice to low-dose radiation (LDR). This study aims to investigate the different responses of tumor cells and normal cells to LDR.

Material and methods: Survival fraction, micronucleus frequency, and cell cycle of Lewis cells and primary human fibroblast AG01522 cells were measured. S180 sarcoma cells were implanted in mice, and tumor sizes were measured in vivo. Results: In response to LDR exposure in vitro, a stimulating effect was observed in AG01522 cells but not in Lewis cells. Low-dose radiation did not cause an adaptive response in the Lewis cell cycle. Lack of an LDR-induced radioadaptive response in tumor cells was observed in tumor-bearing mouse models. Furthermore, a higher apoptotic effect and lower expression of the antiapoptosis gene $\mathrm{Bcl}-2$ were found in tumor cells of tumor-bearing mice exposed to D1 + D2 than those in tumor cells of tumor-bearing mice exposed to D2 alone.

Conclusions: Different responses of tumor cells and normal cells to LDR were found. Low-dose radiation was found to stimulate the growth of normal cells but not of tumor cells in vitro and in vivo, which is a very important and clinically relevant phenomenon.

Key words: low dose radiation, adaptive response, clonogenic survival, cell cycle, tumor cells.

Contemp Oncol (Pozn) 2013; 17 (4): 356-362 DOI: $10.5114 /$ wo.2013.35289

\section{Different responses of tumor and normal cells to low-dose radiation}

\author{
Hongsheng Yu, Ning Liu, Hao Wang, Qingjun Shang, Peng Jiang, \\ Yuanmei Zhang
}

Department of Oncology, the Affiliated Hospital of Qingdao University Medical College, Qingdao, China

\section{Introduction}

Low-dose radiation (LDR) is characterized by a low linear energy transfer (LET) radiation dose of less than 0.2 Gy or a high LET radiation dose of less than 0.05 Gy but a radiation dose rate higher than $0.05 \mathrm{mGy} / \mathrm{min}$. In 1984, Olivieri et al. [1] trained human peripheral blood lymphocytes of thymine in media culture containing $3.7 \mathrm{kBq} / \mathrm{ml} 33 \mathrm{H}$ deoxyriboside and then radiated with 150 cGyX. They found that the distortion rate of cells after irradiation was reduced $70 \%$ more than expected. This effect was called an LDR-induced adaptive response. Radioadaptive response describes the ability of LDR to induce cellular changes that alter the level of subsequent radiation-induced damage $[2,3]$. Subsequent research on this topic became a hotspot. Studies have found that normal cells including immune cells, blood cells [4-6], and spermatogonial cells [7] induced by LDR could cause an adaptive response. Thus, LDR improved organism immunity and enhanced the tolerance of normal tissue under radiation. Different biological effects can occur between LDR and highdose radiation. One of the effects of LDR is an adaptive response. An LDR adaptive response is characterized by the induction of radioresistance to subsequent high doses of radiation through LDR pretreatment. This method has been extensively documented by many investigators with different experimental models, including cultured cells and experimental animals [8-11]. Experimental studies have proven that low doses of ionizing radiation induce various cancer types with various effects, including radioadaptive response, activation of immune functions, and enhancement of resistance to high-dose radiation at the initial slope of the cell survival curve [4, 12]. In recent years, studies on the effects of LDR have attracted the attention of scientists in radiation research $[12,13]$. Joiner et al. [14] reported that low doses of ionizing radiation demonstrate an unique radiobiological phenomenon: the initial phase of hyperradiosensitivity (HRS) of LDR. Radiation-induced cell cycle arrest provides an opportunity for cells to repair DNA damage before entering the mitotic phase [15]. The discovery that HRS does not stimulate cellular repair mechanisms, such as those observed at higher doses, may explain the absence of induction of radioresistance with HRS, as measured in vitro [16].

Some researchers have concentrated on the immune system $[1,11,17,18]$, the hematopoietic system [12, 19, 20], and normal tissue cells. However, studies on the direct response to tumor cells have been few. The different adaptive responses of individuals suggest that different cell types also exhibit different adaptive responses. The current mechanism of the LDR-induced adaptive response is unclear. The LDR-induced adaptive response has been associated with cell cycle arrest [5, 6, 9]. However, some studies have reported that only a slight correlation exists between the two [4]. A literature review revealed that certain tumor cells are resistant to the LDR-induced radioadaptive response or show a distinct pattern from normal cells for interval times between LDR and subsequently large doses of radiation [21, 22]. If the LDR-induced adaptive response is only exhibited by normal cells and not by tumor cells, then 
the exposure time and doses of LDR can be manipulated in favor of normal tissues and not of tumor cells to induce a radioadaptive response (radioresistance) in cancer patients. Under such conditions, increasing radiotherapy doses may increase radiotherapeutic efficiency for tumor cells.

In this study, we demonstrated stimulation of both erythrocyte immune function and superoxide dismutase (SOD) activity in tumor-bearing mice in response to whole-body 75 mGy X-rays. In addition, we enhanced the chemotherapeutic effect by exposing tumor-bearing mice to LDR $[4,17]$. We investigated the different responses of tumor cells and normal cells to LDR. This study aims to systemically determine whether LDR induces an adaptive response in tumor cells in vitro and in vivo.

\section{Material and methods}

\section{Cell culture}

Lewis cells, S180 tumor cells, and primary human fibroblasts (AG01522) were procured from the Center Laboratory of the Affiliated Hospital of Qingdao University Medical College. The cells were cultured in RPMI1640 medium containing $10 \%$ fetal bovine serum, $100 \mathrm{U} / \mathrm{ml}$ penicillin, and $100 \mathrm{\mu g} / \mathrm{ml}$ streptomycin sulfate.

\section{Irradiation}

Protocols for animal care and experimental management were approved by the Affiliated Hospital of Qingdao University Scientific Committee, Qingdao Animal Research Institute, China. For in vitro studies, cultured tumor cells were divided into sham-irradiated (control) and irradiated with D1 (75 mGy), D2 (2, 4, and 6 Gy), or D1 + D2 after D1. Growing cells were exposed to $\gamma$-ray irradiation using an FCC-7000 center Rotary 60 Co therapy machine. We used low-dose 75 mGy at a dose rate of $3.6 \mathrm{cGy} / \mathrm{min})$ and high-dose (2, 4, or $6 \mathrm{~Gy}$ at a dose rate of $44.15 \mathrm{cGy} / \mathrm{min}$ ) radiation. High-dose radiation was administered $8 \mathrm{~h}$ after LDR. At the same time, we set a group as the control group. Three samples were taken each time at different situations. For the in vivo study, tumor-bearing mice were divided into sham-irradiated (control) or whole-body irradiated with D1 (75 mGy at a dose rate of $3.6 \mathrm{cGy} / \mathrm{min}$ ), D2 (8 Gy at a dose rate of $44.15 \mathrm{cGy} / \mathrm{min}$ ), or D1 + D2 at $8 \mathrm{~h}$ intervals between D1 and D2. The tumorbearing mice were killed $20 \mathrm{~d}$ after D2.

\section{Survival fraction}

After ionization radiation, the cells were digested and counted. A certain number of cells (control group and D1 group 300 cells/dish; D2 group and D1 + D2 group 600 cells/dish) were injected, with three dishes for each dose group. The cells were trained for $10 \mathrm{~d}$ after vaccination at $37^{\circ} \mathrm{C}$ in $5 \% \mathrm{CO}_{2}$ atmosphere and saturated in a humidity training box. During training, a training solution was added to keep the cells from drying. After 10 days, the medium was discarded. The cells were gently washed with phosphate-buffered saline (PBS) and fixed with $75 \%$ ethanol for $30 \mathrm{~min}$ to $60 \mathrm{~min}$. After air-drying, the cells were dyed with $8 \%$ Giemsa for $1 \mathrm{~h}$. Subsequently, the number of cell clones was counted (count $\geq 50$ cells of single clone) using the following formulas: cloning efficiency $(\%)=($ number of cloned cells/inoculation cell count $) \times$ $\times 100 \%$ and survival fraction $=($ clone forming rate after irradiation $/$ cell clone forming rate without irradiation) $\times 100 \%$.

The results obtained would reflect the cell viability. The higher the number, the stronger the viability would be.

\section{Micronucleus assay}

First cleavage micronucleus induction was evaluated in situ using the cytokinesis-block technique [23]. Immediately after irradiation, the cells were harvested and replanted into $60 \mathrm{~mm}$ dishes. Four hours after replanting, cytochalasin B was added to the culture medium for a final concentration of $1.5 \mu \mathrm{g} / \mathrm{ml}$. The optimum frequency of binucleated cells was determined through these subsequent steps. The cultures were maintained at $37^{\circ} \mathrm{C}$ for $48 \mathrm{~h}$ to $72 \mathrm{~h}$, harvested, treated with $0.075 \mathrm{M} \mathrm{KCl}$, and fixed ( $3: 1$ methanol : acetic acid). The cell suspension was transferred onto glass microscope slides and air-dried overnight.

\section{Determination of cell cycle}

To make a single-cell solution, the cells were digested, washed with PBS solution, and centrifuged (at $500 \mathrm{r} / \mathrm{min}$ to $1000 \mathrm{r} / \mathrm{min}$ for $5 \mathrm{~min}) 30 \mathrm{~min}, 90 \mathrm{~min}, 3 \mathrm{~h}, 6 \mathrm{~h}, 12 \mathrm{~h}, 24 \mathrm{~h}$, and $48 \mathrm{~h}$ after irradiation. The cells were exposed to the therapy machine, counted, and centrifuged at $1500 \mathrm{r} / \mathrm{min}$ for $5 \mathrm{~min}$. The supernatant was removed. After oscillation, the cells were prepared into a single-cell suspension and washed with the remaining PBS liquid. Subsequently, we added $500 \mu \mathrm{l}$ iodine solution of totally $\mathrm{c}(50 \mu \mathrm{g} / \mathrm{ml})$ and 2 UL RNAase $(1 \mathrm{mg} / \mathrm{ml})$. The resulting mixture was placed in the dark for $30 \mathrm{~min}$ at $37^{\circ} \mathrm{C}$. Cell cycle percentage was then detected using a flow type cell instrument (United States, BD Company).

\section{Tumor sizes}

Tumor growth was monitored by measuring tumor diameters in two dimensions using a caliper every other day. Tumor sizes were calculated as follows:

$\left[\mathrm{L}\right.$ (long diameter) $\times \mathrm{S}^{2}$ (short diameter) $] / 2$.

After the mice were killed $20 \mathrm{~d}$ after D2, tumor inhibition (\%) was calculated as:

(tumor volume in sham - tumor volume in irradiated groups)/ tumor volume in sham $\times 100$.

\section{Tumor cell apoptosis}

A sample of the tumor tissue was taken and made into a fresh single-cell suspension mechanically. The tumor cells were isolated, dyed, and collected through flow cytometry (Becton-Dickinson FACS Vantage) using Cellquest 3.1f, as previously reported [23]. The data were analyzed using the ModFit 2.0 software.

\section{Semi-quantitative assay of protein $\mathrm{Bcl}-2$}

A sample of the tumor tissue was collected, fixed in neutral formalin, embedded with paraffin, sliced, dewaxed, dehydrated, added to the monoclonal antibody of protein Bcl-2 and bi-antibody tri-antibody (Beijing Zhongshan Biological Technology Corp., Ltd.), and dyed again. A total of 200 cells were evaluated under a microscope. 


\section{Statistical analysis}

Results were presented as mean \pm standard deviation, and survival score was determined by $X^{2}$ test. Cell cycle was analyzed through one-way repeated measures analysis of variance; $p<0.05$ was considered to indicate statistical significance.

\section{Results}

\section{Survival fraction of Lewis cells}

The clone survival fractions of the D2 and D1 + D2 groups are lower than that of the D1 group $(p<0.01)$. No difference was found between the D2 and D1 + D2 groups ( $p>0.05$ ). Lewis cell survival did not proliferate with exposure to low-dose $75 \mathrm{mGy}$ score before high-dose (2, 4, or 6 Gy) irradiation (Fig. 1A). By contrast, an LDR-induced adaptive response was significantly evident in AG01522 normal cells exposed to the same radiation conditions as the Lewis cells (Fig. 1B). An adaptive response was evident mainly in the D1 + D2 group. The survival fraction of the D1 + D2 group increased compared with that of the D2 group.

\section{Micronucleus assay}

Generally, the percentage of micronucleated cells increased with increasing dose. Each bar represents the mean \pm S.E. of three independent experiments. No statistically significant adaptive response was observed relative to the control for Lewis cells (Fig. 2A). However, for AG01522 normal cells, we observed a peak at intermediate doses followed by a decrease in the percentage of micronucleated cells at higher doses (Fig. 2B).

\section{Cell cycle}

After irradiation for $90 \mathrm{~min}, 3 \mathrm{~h}, 6 \mathrm{~h}$, and $12 \mathrm{~h}$, the cell percentage of the D1 group in the G1 phase was slightly higher than that of the D0 group. After irradiation for $30 \mathrm{~min}$, $24 \mathrm{~h}$, and $48 \mathrm{~h}$, the percentage was similar to that of the D0 group. However, no statistically significant differences were observed in the cell percentage between the D1 and D0 groups ( $p>0.05$, Table 1$)$. These results suggest that Lewis cell cycle arrest could not be induced by LDR.
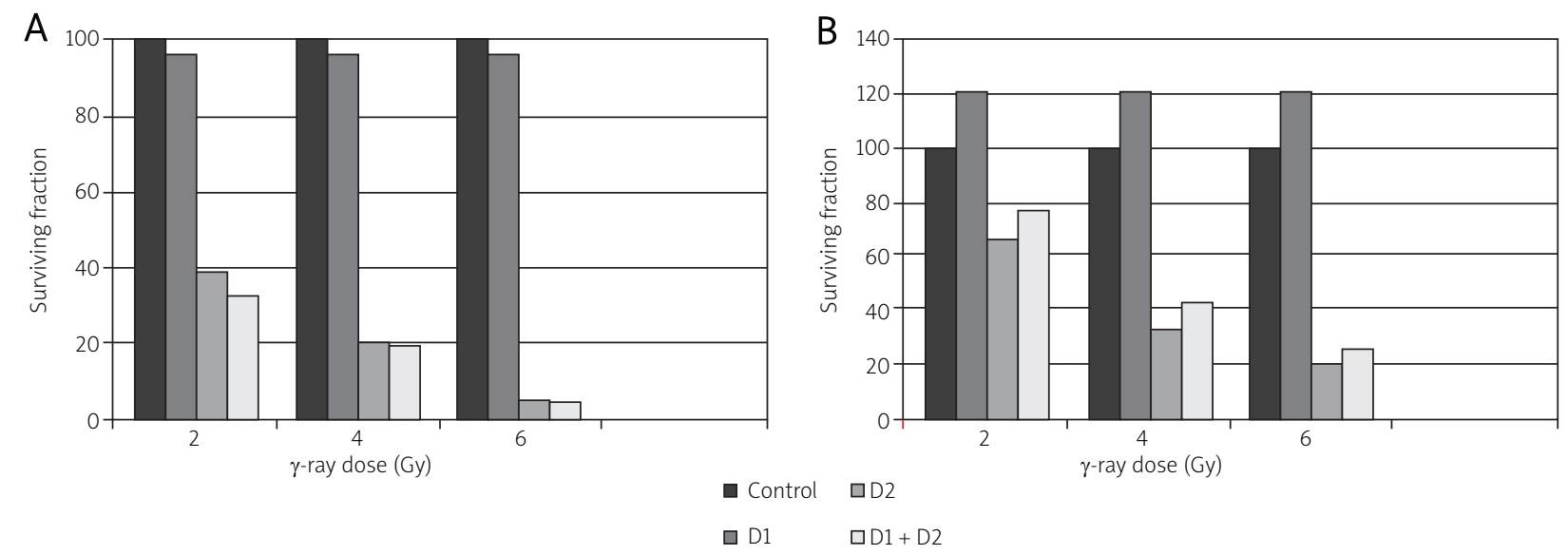

Fig. 1. Surviving fraction as a function of LDR on subsequent radiation-induced cytotoxic effect. Cell cultures were exposed to low dose ( $75 \mathrm{mGy}$, dose rate of $3.6 \mathrm{cGy} / \mathrm{min}$ ) radiation. After $8 \mathrm{~h}$, the same cultures were exposed to an $\mathrm{x}$-ray challenge dose of 2, 4 or $6 \mathrm{~Gy}$. Clonogenic survival was measured 10-14 days post exposure for Lewis cells (A) and AG01522 (B) cell cultures

A

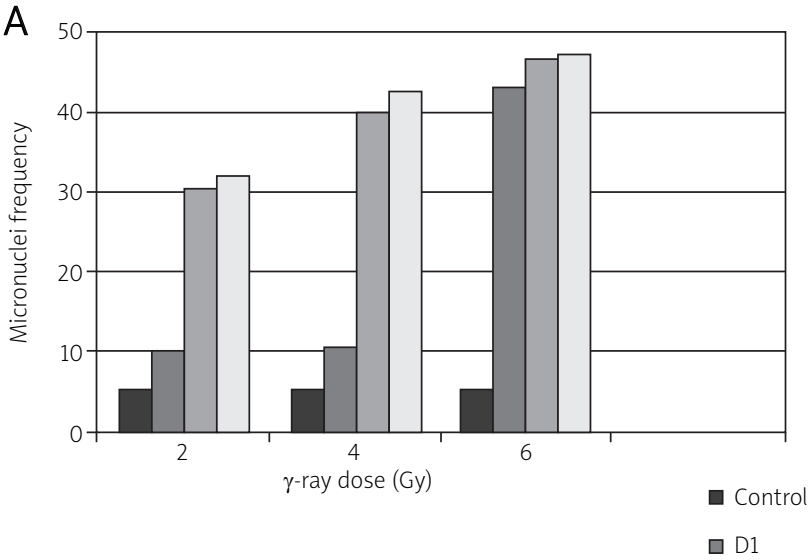

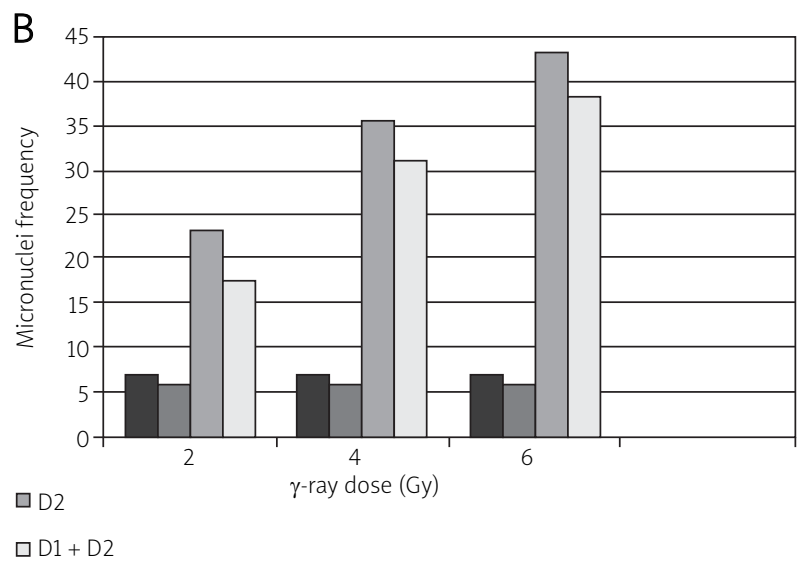

Fig. 2. Percentage of cells in which micronuclei were induced as a function of dose. The fraction of binucleated cells with one or more micronuclei was measured 48 hours post exposure for Lewis cells (A) and 72 hours post exposure for AG01522 (B) cells. Each bar represents the mean \pm S.E. of three independent experiments 
Table 1. D0 and D1 group comparison of the unit cell of Lewis cells in vitro $(\bar{x} \pm \mathrm{s}, \%)$

\begin{tabular}{lccc} 
& \multicolumn{3}{c}{ Cell cycle } \\
\cline { 2 - 4 } & G1/G0 & $\mathrm{S}$ & $\mathrm{G} 2 / \mathrm{M}$ \\
\hline Control group & $26.3 \pm 1.5$ & $67.0 \pm 1.8$ & $6.7 \pm 0.9$ \\
$30 \mathrm{~min}$ & $25.7 \pm 3.6$ & $66.2 \pm 3.7$ & $8.1 \pm 1.4$ \\
\hline $90 \mathrm{~min}$ & $27.1 \pm 1.7$ & $62.1 \pm 2.1$ & $10.8 \pm 0.3$ \\
$3 \mathrm{~h}$ & $29.9 \pm 3.1$ & $62.5 \pm 9.5$ & $7.6 \pm 0.7$ \\
$6 \mathrm{~h}$ & $31.6 \pm 5.5$ & $63.7 \pm 0.9$ & $4.7 \pm 0.9$ \\
$12 \mathrm{~h}$ & $31.4 \pm 1.8$ & $63.3 \pm 2.9$ & $5.3 \pm 1.1$ \\
$24 \mathrm{~h}$ & $26.0 \pm 0.8$ & $63.1 \pm 3.2$ & $10.9 \pm 1.8$ \\
$48 \mathrm{~h}$ & $26.1 \pm 5.7$ & $67.8 \pm 0.6$ & $6.1 \pm 1.9$
\end{tabular}

Note: compared with control group, ${ }^{*} p<0.05 ;{ }^{* *} p<0.01$

Table 3. D0 and D1 + D2 group comparison of the unit cell of Lewis cells in vitro $(\bar{x} \pm s, \%)$

\begin{tabular}{lccc} 
Time after irradiation & \multicolumn{3}{c}{ Cell cycle } \\
\cline { 2 - 4 } & $\mathrm{G} 1 / \mathrm{G} 0$ & $\mathrm{~S}$ & $\mathrm{G} 2 / \mathrm{M}$ \\
\hline Control group & $26.3 \pm 1.5$ & $67.0 \pm 1.8$ & $6.7 \pm 0.9$ \\
\hline $30 \mathrm{~min}$ & $28.1 \pm 2.8$ & $60.7 \pm 2.1$ & $11.2 \pm 0.9$ \\
\hline $90 \mathrm{~min}$ & $31.4 \pm 0.9$ & $63.1 \pm 12.9$ & $5.5 \pm 3.7$ \\
\hline $3 \mathrm{~h}$ & $33.9 \pm 1.1$ & $62.6 \pm 1.1$ & $3.5 \pm 1.9$ \\
\hline $6 \mathrm{~h}$ & $43.2 \pm 7.5^{* *}$ & $51.9 \pm 4.3$ & $4.9 \pm 1.5$ \\
\hline $12 \mathrm{~h}$ & $51.1 \pm 5.8^{* *}$ & $43.8 \pm 9.0$ & $5.1 \pm 0.8$ \\
\hline $24 \mathrm{~h}$ & $53.7 \pm 3.0^{* *}$ & $41.3 \pm 14.4$ & $6.0 \pm 0.3$ \\
\hline $48 \mathrm{~h}$ & $52.8 \pm 9.0^{* *}$ & $42.5 \pm 10.7$ & $4.7 \pm 0.9$
\end{tabular}

Note: compared with control group, ${ }^{*} p<0.05 ;{ }^{* *} p<0.01$

After irradiation for 6,12 , and $24 \mathrm{~h}$, the cell percentage of the D2 group in the G1 phase was significantly higher than that of the D0 group ( $p<0.05$, Table 2). Thus, G1 phase arrest of Lewis cells might be induced by high doses of radiation. After irradiation for $48 \mathrm{~h}$, the cell cycle arrest did not terminate.

After irradiation for 6,12 , and $24 \mathrm{~h}$, the cell percentage of the D1 + D2 group in the G1 phase was significantly higher than that of the D0 group ( $p<0.01$, Table 3). Thus, the $\mathrm{D} 1$ + D2 group might have a G1 phase arrest. After irradiation for $48 \mathrm{~h}$, the cell cycle arrest did not terminate. Thus, LDR did not induce an adaptive response in the Lewis cell cycle.

\section{Effect of low-dose radiation on tumor growth in vitro}

Kunming mice were implanted with ascites sarcoma S180 cells that were originally derived from mice. These tumorbearing mice were pre-irradiated with $75 \mathrm{mGy}$ of $\gamma$-rays (D1) at $8 \mathrm{~h}$ prior to $8 \mathrm{~Gy}$ of whole-body $\gamma$-ray radiation (D2). The mice were sacrificed $20 \mathrm{~d}$ after D2, and tumor inhibition was evaluated (Fig. 3). The pre-exposure to D1 significantly enhanced the tumor killing effects of D2. This result suggests that the tumor-bearing mouse models did not exhibit an LDRinduced radioadaptive response in tumor cells.
Table 2. D0 and D2 group comparison of the unit cell of Lewis cells in vitro $(\bar{x} \pm s, \%)$

\begin{tabular}{lccc} 
Time after irradiation & \multicolumn{3}{c}{ Cell cycle } \\
\cline { 2 - 4 } & G1/G0 & $\mathrm{S}$ & $\mathrm{G} 2 / \mathrm{M}$ \\
\hline Control group & $26.3 \pm 1.5$ & $67.0 \pm 1.8$ & $6.7 \pm 0.9$ \\
\hline $30 \mathrm{~min}$ & $27.6 \pm 5.1$ & $62.6 \pm 0.8$ & $9.9 \pm 3.0$ \\
\hline $90 \mathrm{~min}$ & $29.9 \pm 0.7$ & $61.4 \pm 3.9$ & $8.7 \pm 0.4$ \\
\hline $3 \mathrm{~h}$ & $30.1 \pm 1.8$ & $63.2 \pm 6.0$ & $6.7 \pm 2.1$ \\
\hline $6 \mathrm{~h}$ & $37.8 \pm 8.3^{*}$ & $55.3 \pm 3.2$ & $6.9 \pm 1.7$ \\
\hline $12 \mathrm{~h}$ & $50.7 \pm 7.4^{* *}$ & $44.4 \pm 6.8$ & $4.9 \pm 2.7$ \\
\hline $24 \mathrm{~h}$ & $46.2 \pm 0.3^{* *}$ & $47.7 \pm 10.3$ & $6.1 \pm 0.7$ \\
\hline $48 \mathrm{~h}$ & $49.3 \pm 4.2^{* *}$ & $44.8 \pm 7.1$ & $5.9 \pm 1.1$
\end{tabular}

Note: compared with control group, ${ }^{*} p<0.05 ;{ }^{* *} p<0.01$

Table 4. Effects of low-dose radiation on the expression of protein $\mathrm{Bcl}-2$ in tumor cells

\begin{tabular}{lcccccc} 
Time after & Groups & $n$ & \multicolumn{5}{c}{$n$} \\
\cline { 3 - 7 } irradiation (h) & & & - & + & ++ & +++ \\
24 & Control & 15 & 4 & 6 & 4 & 1 \\
& D1 & $15^{*}$ & 9 & 6 & 0 & 0 \\
48 & Control & 15 & 4 & 8 & 3 & 0 \\
& D1 & 15 & 3 & 7 & 4 & 1
\end{tabular}

${ }^{*} u=2.2136, p<0.05$

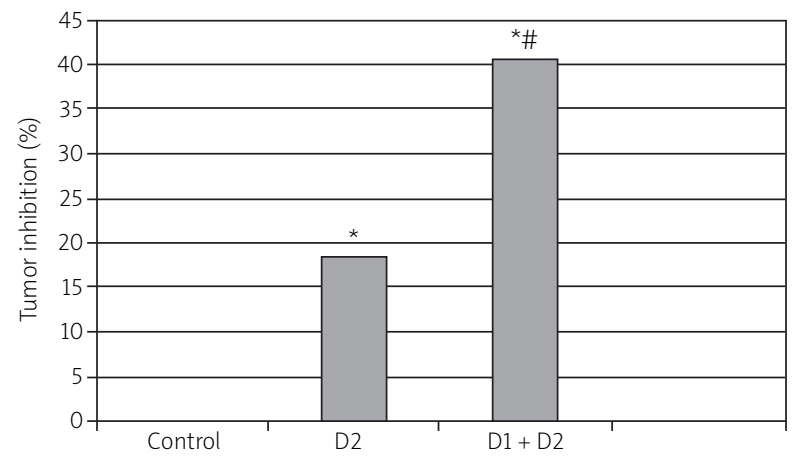

Fig. 3. Effect of LDR on D2 therapy in tumor-bearing Kunming mouse model. Kunming mice were implanted with mouse S180 tumor cells and irradiated with $75 \mathrm{mGy}$ of $\gamma$-rays as D1, and $8 \mathrm{~h}$ late irradiated with 8 Gy of $\gamma$-rays as D2. The tumor inhibition (\%) was calculated on day 20 when these mice were killed, as described in Fig. 3. The data are presented as mean \pm S.E. from 15 mice. ${ }^{*} p<0.05$ vs. corresponding controls; ${ }^{*} p<0.05$ vs. corresponding D2

\section{Semi-quantitative analysis of protein $\mathrm{Bcl}-2$} in tumor cells

At $24 \mathrm{~h}$ after LDR, the expression of protein $\mathrm{Bcl}-2$ in the D1 tumor cells decreased compared with that in the control group. However, at $48 \mathrm{~h}$ after LDR, no significant difference was found between the two groups (Figs. 4-5 and Table 4).

\section{Observation of results via electron microscopy}

The terminal processes of apoptosis and phagocytosis of apoptotic bodies by macrophages were observed under trans- 


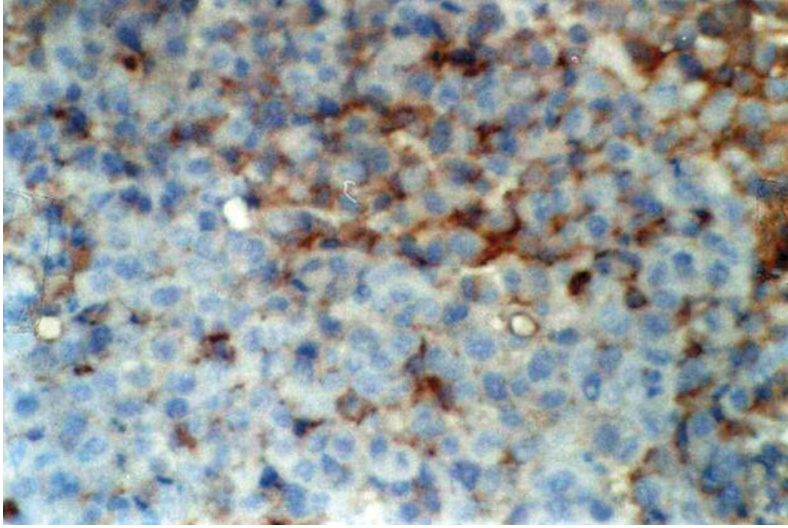

Fig. 4. Immunohistochemistry showing $\mathrm{Bcl}-2(+++)$ in control group at $24 \mathrm{~h}$ after LDR. Magnification $400 \times$

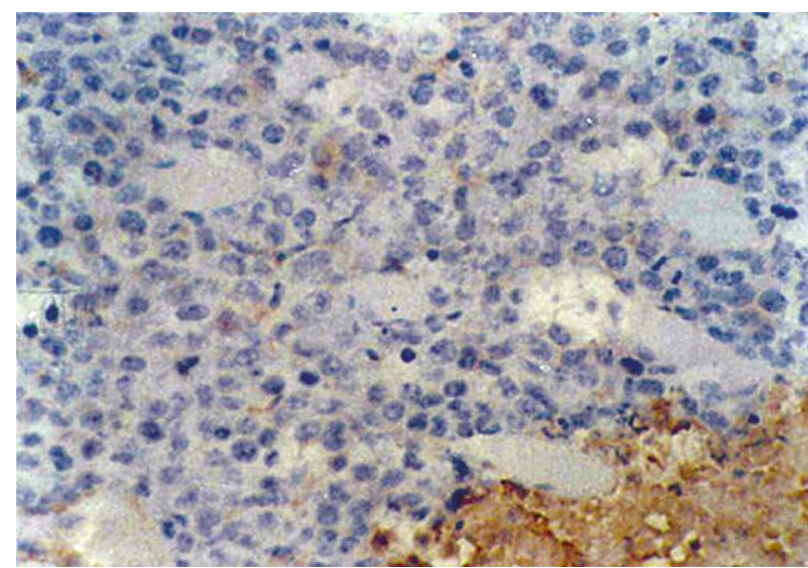

Fig. 5. Immunohistochemistry showing $\mathrm{Bcl}-2(-)$ in group D1 at $24 \mathrm{~h}$ after LDR. Magnification $400 \times$

mission electron microscopy. Thus, LDR is further proven to induce tumor cell apoptosis by increasing the host body's immune function (Figs. 6-7).

\section{Discussion}

Some scholars [24-26] considered the adaptive response of normal cells as a universal biological phenomenon. The LDR-induced adaptive response could depend on many factors, including the type of cell. Available studies on the relationship between tumor cells and the LDR-induced adaptive response are few, and a significant difference was found among the results. Low-dose radiation has a slight effect on tumor cells in vitro. Zhang [27] found that, after 75 mGy irradiation, the cell cycle of A549 lung cancer cells cultured in vitro does not differ significantly from that in the control group.

The present study demonstrated that LDR does not induce a radioadaptive response in Lewis cells in vitro. The in vitro finding was validated under in vivo conditions using tumorbearing animal models. We further demonstrated that cell death and the cell death-related gene $\mathrm{Bcl}-2$ decreased in the D1 + D2 group. Therefore, the lack of induction of a radioadaptive response in tumor cells in vivo may be related to the increase in apoptotic effect in the D1 + D2 group.

Our study supports that LDR is unable to induce a radioadaptive response in tumor cells (Lewis and S180 cells) but does not support that LDR is also unable to induce a radioadaptive response in a normal cell line (AG01522).

Apoptosis, or programmed cell death, is a normal physiological mechanism and a cellular defense response. The role of apoptosis in the LDR-induced adaptive response is still unclear. Previous literature [28] has proven that D1 radiation $(<0.12 \mathrm{~Gy})$ significantly reduces the number of apoptotic cells and stimulates cell proliferation.

Some scholars thought D1 radiation activated the apoptosis system and promoted clearance of those cells with DNA damage after D2 irradiation. However, the ultimate phenomenon was the adaptive response of chromosome aberration reduction. Liu et al. [29] radiated EL-4 lymphoma cells in advance with $75 \mathrm{mGy}$ (D1) X-rays at dose rates of 6.25, 12.5, $25,50,100$, and $200.00 \mathrm{mGy} / \mathrm{min}$. After $6 \mathrm{~h}$, the dose was adjusted to $1.5 \mathrm{~Gy}$ (D2). After $18 \mathrm{~h}$, the apoptosis percentage and percentage change of the phase of the cell cycle process were observed. In this experiment, cell inoculation was conducted after ionizing radiation, and clone live score was counted to assess cell viability. Its value is proportional to capacity and cell survival. In this experiment, the survival score of the D2 and D1 + D2 groups was lower than that of the D1 group ( $p<0.01$ ). However, no significant difference was found between the D2 and D1 + D2 groups $(p>0.05)$. This result indicates that no adaptive response was induced by the high doses of radiation on Lewis lung carcinoma cells after LDR pretreatment.

The apoptotic cell death in S180 tumor cells increased $20 \mathrm{~d}$ after D2 radiation (Fig. 3). This result is also consistent with the findings of Chen et al. [30], who reported enhanced apoptotic cell death of MOLT-4 cells in response to LDR given $12 \mathrm{~h}$ prior to a challenge dose of $5 \mathrm{~Gy}$. Therefore, LDR does not induce an adaptive response or even enhance D2-induced cytotoxic effects on tumor cells, which may contribute to the lack of LDR-induced adaptive response in tumor cells under in vivo conditions.

Several studies have reported on the LDR-induced adaptive response. However, the mechanism of the adaptive response is not clear. A large number of cells in the body system, whether caused by gene expression or not, produce proteins or enzymes to eliminate radical scavenging in order to repair damaged DNA. Eventually, the injury is cleared up through cell apoptotic mechanisms, or attributed with resistance to successively withstand higher doses of radiation.

Zhang et al. [27] found that LDR could induce 2BS (human embryonic lung fibroblasts) to produce an adaptive response. In addition, they found that cells administered with both lowdose and high-dose irradiation for 30 min produce $G 2$ phase cell cycle arrest. This phenomenon happened $6 \mathrm{~h}$ earlier than the high-dose irradiation group, and cell cycle arrest recovered to the normal cell cycle after $24 \mathrm{~h}$. These results suggest that the adaptive response is closely related to cell cycle control. However, Dolling [31] reported that wild-type and G1 and G2 cycle arrest-defective yeast cells produce an adaptive response after $L D R$, whereas deficient yeast cells repaired repeatedly do not produce an adaptive response after LDR. This result suggests that a slight correlation exists between adaptive response and cell cycle arrest. Recombination repair ability and improvement was the main reason for the 
adaptive response. The effect of different doses of radiation on cell cycle regulation was studied in this experiment to clarify the adaptive response mechanism further.

Survival tumor had unlimited ability to proliferate. Cell division and proliferation experienced $\mathrm{G} 1, \mathrm{~S}, \mathrm{G} 2$, and $\mathrm{M}$ phase, and were carried out under strict monitoring of a series of test points. Four main points were identified: G1/S, S, G2/M, and spindle assembly checkpoint. Each inspection point is composed of three parts: detectors, sensors, and effectors. When DNA is damaged (i.e., abnormal copy of DNA or incomplete spindle formation), the cell cycle is arrested. DNA damage induced by ionizing radiation could cause cell cycle arrest. In this experiment, the cell percentage of the D1 group in the G1 phase was slightly higher than that of the D0 group after irradiation for $90 \mathrm{~min}, 3 \mathrm{~h}, 6 \mathrm{~h}$, and $12 \mathrm{~h}$. How ever, the differences were not statistically significant $(p>0.05)$. These findings might be related to the slight effect of LDR on the cell injury of Lewis and rapid DNA damage repair.

Jiang et al. [24] revealed that LDR-induced U251 (human glioma) and $\mathrm{NCl}-\mathrm{H} 446$ (small-cell lung cancer) do not produce an adaptive response. Immunohistochemistry results demonstrated that LDR could not affect P53 mRNA and protein expression levels. However, LDR and a high dose of radiation could induce a significant increase in the expression of P53 mRNA and protein level. P53 is the key protein of G1 phase arrest by inducing the enhanced expression of $P 21$ and GADD45, and enabling cell cycle arrest at the G1 phase. After the cell cycle arrest, cellular repair mechanisms started. If the DNA was not damaged severely, cells would remain alive at cell cycle arrest after being repaired completely. If the damage was heavier and could not be repaired, the cell initiated apoptosis to ensure the stability of gene forms.

The effects of LDR on the tumor cells of mice at the cellular, molecular, and even genetic levels, following the improvement of the body's immune function, have been reported in a few studies. The expression of apoptosis-related protein $\mathrm{BCl}-2$ was related to tumor cell apoptosis. The expression of protein $\mathrm{Bcl}-2$ decreased at $24 \mathrm{~h}$ and normalized at $48 \mathrm{~h}$. This finding is consistent with the fact that apoptosis is active programmed cell death. Cells synthesize apoptosis-related proteins to switch on the apoptotic program before apoptosis occurs. Primary and terminal processes of apoptosis, as well as the images of phagocytosis of apoptotic bodies by macrophages, were observed under transmission electron microscopy, which further confirms the conclusions.

In the present study, we demonstrated that LDR (75 mGy $\gamma$-rays) can stimulate the proliferation of normal human cells but not of solid tumor human cells in vitro and in vivo. The biological consequences of the seemingly selective stimulation of normal tissue over tumor cells in vivo remain unclear. However, an LDR-induced adaptive response of the hematological and immunological systems may benefit therapy because radiotherapy and chemotherapy suppress the immunological and hematological systems. If LDR can stimulate normal tissue cell growth but not tumor cell growth, it may help the recovery of damaged normal cells adjacent to tumor cells after radiotherapy.

Our two previous studies may indirectly indicate the feasibility of this suggestion. Stimulation of both erythrocyte

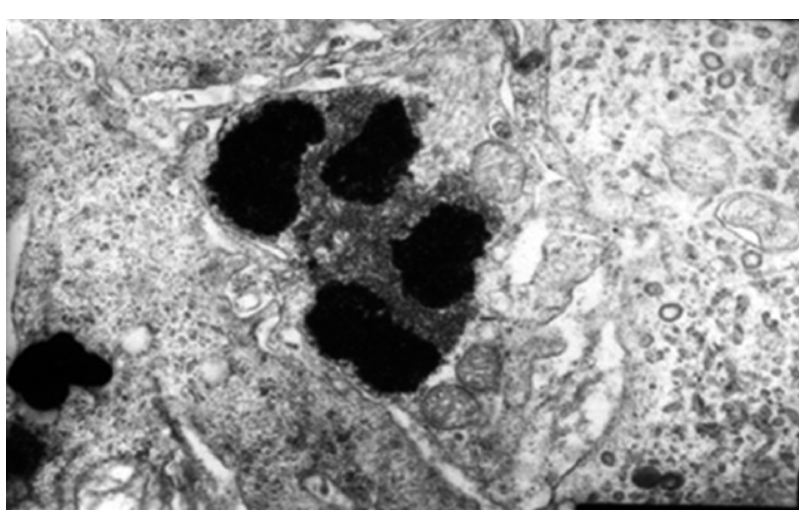

Fig. 6. Group D1 at $48 \mathrm{~h}$ after LDR: phenomenon of the terminal process of apoptosis. Magnification $15000 \times$

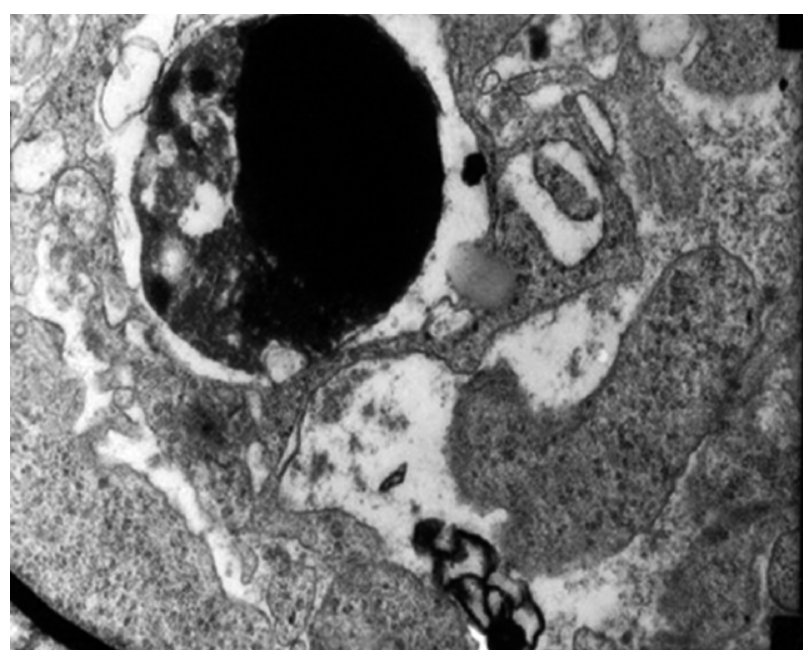

Fig. 7. Group D1 at $48 \mathrm{~h}$ after LDR: phenomenon of macrophages phagocytosing apoptotic bodies and forming secondary lysosome. Magnification $15000 \times$

immune function and SOD activity in tumor-bearing mice in response to whole-body $75 \mathrm{mGy}$ X-rays has been observed [17]. In addition, enhanced chemotherapeutic effects from exposing tumor-bearing mice to LDR have been reported [4]. Based on this and our previous studies, we can conclude that LDR stimulates cell proliferation in several normal tissues, including hematopoietic progenitor cell proliferation and peripheral mobilization, and does not induce the same stimulating effect in tumor cells. Up to 75 mGy of X-rays as LDR can stimulate bone marrow stem cells [32] and is also a tolerable dose for patients [33]. Therefore, the findings of the current study may have a great potential for clinical application in cancer radiotherapy.

The authors declare no conflict of interest.

\section{References}

1. Olivieri G, Bodycote J, Wolff S. Adaptive response of human lymphocytes to low concentrations of radioactive thymidine. Science 1984; 223: 594-7. 
2. Tapio S, Jacob V. Radioadaptive response revisited. Radiat Environ Biophys 2007; 46: 1-12.

3. Sowa MB, Goetz W, Baulch JE, Lewis AJ, Morgan WF. No evidence for a low linear energy transfer adaptive response in irradiated RKO cells. Radiat Prot Dosimetry 2011; 143: 311-4.

4. Yu HS, Xue HW, Guo CB, Song AQ, Shen FZ, Liang J, Deng C. Low dose radiation increased the therapeutic efficacy of cyclophosphamide on s(180) sarcoma bearing mice. J Radiat Res (Tokyo) 2007; 48: 281-8.

5. Rzeszowska-Wolny J, Przybyszewski WM, Widel M. Ionizing radiation-induced bystander effects, potential targets for modulation of radiotherapy. Eur J Pharmacol 2009; 625: 156-64.

6. Gong SL, Liu SC, Liu JX, Zhang YC, Liu SZ. Adaptive response of thymocyte apoptosis and cell cycle progression induced by low dose X-ray irradiation in mice. Biomed Environ Sci 2000; 13: 180-8.

7. Liu GW, Gong PS, Zhao HG, Wang Z, Lv WT, Jiang XY, Gong SL. Low dose radiation-induced apoptosis in mouse spermatogenic cells and p53 gene expression of adaptive response. Chin J Radiological Health 2005; 14: 161-3.

8. Feinendegen LE. Evidence for beneficial low level radiation effects and radiation hormesis. Br J Radiol 2005; 78: 3-7.

9. Wang GJ, Cai L. Induction of cell-proliferation hormesis and cell-survival adaptive response in mouse hematopoietic cells by whole-body low-dose radiation. Toxicol Sci 2000; 53: 369-76.

10. Cai $L$. Research of the adaptive response induced by low-dose radiation: where have we been and where should we go. Hum Exp Tox icol 1999; 18: 419-25.

11. Cheda A, Wrembel-Wargocka J, Lisiak E, Nowosielska EM, Marciniak M, Janiak MK. Single low doses of $X$ rays inhibit the development of experimental tumor metastases and trigger the activities of NK cells in mice. Radiat Res 2004; 161: 335-40.

12. Chen SL, Cai L, Meng QY, Xu S, Wan H, Liu SZ. Low-dose whole-body irradiation (LD-WBI) changes protein expression of mouse thymocytes: Effect of a LD-WBI-enhanced protein RIP10 on cell proliferation and spontaneous or radiation-induced thymocyte apoptosis. Toxicol Sci 2000; 55: 97-106.

13. Safwat A. The immunobiology of low-dose total-body irradiation: more questions than answers. Radiat Res 2000; 153: 599-604.

14. Joiner MC, Marples B, Lambin P, Short SC, Turesson I. Low-dose hypersensitivity: current status and possible mechanisms. Int J Radiat Oncol Biol Phys 2001; 49: 379-89.

15. Vávrová J, Mareková M, Vokurková D. Radiation-induced apoptosis and cell cycle progression in tp53-deficient human leukemia cell line hl-60. Neoplasma 2001; 48: 26-33.

16. Short SC, Kelly J, Mayes CR, Woodcock M, Joiner MC. Low-dose hypersensitivity after fractionated low-dose irradiation in vitro. Int J Radiat Biol 2001; 77: 655-64.

17. Yu HS, Song AQ, Lu YD, Qiu WS, Shen FZ. Effects of low-dose radiation on tumor growth, erythrocyte immune function and SOD activity in tumor-bearing mice. Chin Med J (Engl) 2004; 117: 1036-9.

18. Nowosielska EM, Wrembel-Wargocka J, Cheda A, Lisiak E, Janiak MK. Enhanced cytotoxic activity of macrophages and suppressed tumor metastases in mice irradiated with low doses of X-rays. J Radiat Res 2006; 47: 229-36.

19. Yu HS, Li Y, Wang ZM. Effects of low dose pre-irradiation on the toxicity of cyclophosphammide. Chinese-German J Clin Oncol 2011; 10: 70-6.

20. Kojima S, Ishida H, Takahashi M, Yamaoka K. Elevation of glutathione induced by low-dose gamma rays and its involvement in increased natural killer activity. Radiat Res 2002; 157: 275-80.

21. Park SH, Lee Y, Jeong K, Yoo SY, Cho CK, Lee YS. Different induction of adaptive response to ionizing radiation in normal and neoplastic cells. Cell Biol Toxicol 1999; 15: 111-9.

22. Miyamoto A, Shibamoto Y, Sugie C, Ito M, Ayakawa S. Absence of radioadaptive responses in four cell-lines in vitro as determined by colony formation assay. Kurume Med J 2006; 53: 1-5.

23. Sowa MB, Goetz W, Baulch JE, et al. Lack of evidence for low-LET radiation induced bystander response in normal human fibroblasts and colon carcinoma cells. Int J Radiat Biol 2010; 86: 102-13.

24. Jiang H, Li W, Li X, Cai L, Wang G. Low-dose radiation induces adaptive response in normal cells, but not in tumor cells: in vitro and in vivo studies. Radiat Res 2008; 49: 219-30.
25. Schaffer M, Schwarz SB, Kulka U, Busch M, Dühmke E. Adaptive doses of irradiation-an approach to a new therapy concept for bladder cancer Radiat Environ Biophys 2004; 43: 271-6.

26. Seong J, Kim SH, Pyo HR, Chung EJ, Suh CO. Effect of low-dose radiation on induction of an apoptotic adaptive response in the murine system. Radiat Environ Biophys 2001; 40: 335-9.

27. Zhang ZC, Jia TZ, Zhu YB. 2BS and A549 cell adaptive response induced by low dose radiation research. Chin J Radiological Med Protect 2001; 21: 107-10.

28. Cai L, Cherian MG. Adaptive response to ionizing radiation induced chromosome aberrations in rabbit lymphocytes: effect of p re-exposure to zinc and copper salts. Mutat Res 1996; 369: 233-41.

29. Liu SC, Zhao WJ, Lv G, Li YB, Kang SA, Gong SL. EL-4 lymphoma cells induced by low dose radiation on apoptosis and cell cycle progression of adaptive response of dose-rate effects. J Jilin University 2008; 34: 24-7.

30. Chen Z, Sakai K. Enhancement of radiation-induced apoptosis by preirradiation with low-dose X-rays in human leukemia MOLT-4 cells. J Radiat Res 2004; 45: 239-43.

31. Dolling JA, Boreham DR, Brown DL, Mitchel RE, Raaphorst GP. Modulation of radiation-induced strand break repair by cisplatin in mammalian cells. Radiat Biol 1998; 74: 61-9.

32. Li W, Wang G, Cui J, Xue L, Cai L. Low-dose radiation (LDR) induces hematopoietic hormesis: LDR-induced mobilization of hematopoietic progenitor cells into peripheral blood circulation. Exp Hematol 2004; 32: 1088-96.

33. Safwat A, Schmidt H, Bastholt L, Fode K, Larsen S, Aggerholm N, von der Maase $\mathrm{H}$. A phase II trial of low-dose total body irradiation and subcutaneous interleukin-2 in metastatic melanoma. Radiother Oncol 2005; 77: 143-7.

\section{Address for correspondence}

Hongsheng Yu MD, PhD

Department of Oncology

The Affiliated Hospital of Qingdao University Medical College

16\# Jiangsu Road

Qingdao 266003, China

tel. 86-0532-82913053

e-mail: hongshengyucn@163.com

Submitted: 2.10 .2012

Accepted: $\quad 12.02 .2013$ 